\title{
Implicações filosóficas da Teoria contemporânea do direito: uma análise da aproximação entre teoria e filosofia do direito com vistas a construção do Estado democrático
}

Kátia A. Pastori Terrin ${ }^{1}$

\begin{abstract}
Resumo
Inegável observar a importância da Filosofia nas ciências naturais modernas, bem como no direito. Assim sendo, imperioso se faz destacar a marcante implicação filosófica na teoria contemporânea do direito, além da proximidade entre a Teoria Geral do Direito e a filosofia, apresentando uma proposta de visão global do fenômeno jurídico, reconstruindo conceitos e institutos do direito. Assim sendo, a Teoria Geral do Direito tem por objetivo destacar os elementos essenciais que dominam a elaboração do direito, promovendo a melhora das relações sociais formulando regras justas e aplicando-as de maneira eqüitativa, sem deixa de lado a criação de regras e suas interpretações, bem como a classificação dos fatos jurídicos, construção de teorias e elaboração de princípios, sempre com o cuidado constante de garantir a segurança jurídica, com vistas à construção de um Estado Democrático de Direito.
\end{abstract}

Palavras-chave: Teoria do Direito; Filosofia; Estado Democrático; Teoria contemporânea.

\section{Introdução}

A Teoria Geral do Direito, interligada à Filosofia engloba uma série de princípios e aspectos metodológicos, com vistas a proporcionar uma visão global do mundo jurídico e fenomênico.

No plano prático, para a elaboração e aplicação concreta do direito, recorre-se à teoria geral para descobrir, interpretar, executar as soluções possíveis, mormente ante a inegável realidade que as mudanças sociais, econômicas e políticas refletem sobremaneira nas relações humanas e conseqüentemente na liberdade social e vida social. Nesse contexto, o Direito também sofre suas modificações na medida em que em virtude disso, acentua-se 0 debate sobre si, sua importância, funções e até mesmo sobre o papel da justiça.

1 Professora do curso de Direito da Faccar; Pós graduada em Direito Civil e Processo Civil pela Universidade Estadual de Londrina; M estranda em Direito Negocial pela Universidade Estadual de Londrina; Advogada do Núcleo de Estudos e Defesa dos Direitos da Infância e Juventude de Londrina.

Revista de Direito Púbuco, Londrina, V, 4, N. 3, P. 118-135, SET./ DEZ. 2009. 
Dessa forma, no contexto da sociedade contemporânea, o Direito passa a ser visto sob outro ângulo, na medida em que busca acompanhar as evoluções ocorridas.

E é nesse sentido que não há dúvidas de que, sob a ótica do Estado Democrático de Direito, o Direito deve ser visto como instrumento de transformação social, pautando-se em valores como dignidade, solidariedade e na busca pelo reconhecimento dos direitos fundamentais dos cidadãos.

\section{Implicações filosóficas da Teoria Contemporânea do Direito}

A priori, cumpre destacar que originalmente todas as ciências naturais modernas encontram seu lugar dentro da matriz filosófica. 0 mesmo ocorrendo com a Filosofia Moderna do Direito.

Quando nos referimos a diferentes setores do direito, como direito público e privado, penal, constitucional e administrativo, estes vêm conquistando desde algum tempo certa autonomia. Já outros, por muitos considerados com certo grau de problematização, como a Teoria das Normas, Teoria da Legislação e Teoria da Argumentação, migram da filosofia jurídica e hoje se discutem como temas da Teoria do Direito. (ZACCARIA, 2004)

Seguem pertencendo a um vasto âmbito da Filosofia do Direito, mas não somente pelas questões teórico - jurídicas, mas também porque não possuem apenas um critério único que satisfaça e permita a delimitação rigorosa entre Teoria do Direito e Filosofia do Direito.

Dentre as implicações filosóficas da teoria contemporânea do direito, destaca-se a teoria analítica do direito, caracterizada por uma visão empírica e racionalista da investigação filosófica e também por uma atitude propensa ao dualismo metodológico entre proposições descritivas e prescritivas, destacando-se tamanha importância, deste ramo no mundo jurídico.

A segunda seria a teoria sistêmico-funcionalista do direito, surgida com o intuito de adequar a teoria jurídica à complexidade dos elementos de transformação dos sistemas sociais e políticos contemporâneos, ao considerar a teoria do direito como prestação reflexiva do sistema jurídico. 
Em princípio, antes de adentramos na interligação específica entre 0 três ramos abordados pelo autor, cumpre esclarecer que não se pode abordá-las com enfoques mais ou menos importantes. Todas as três possuem fundamental imprescindibilidade.

Observa-se ainda uma profunda interligação entre a filosofia do direito e a dogmática jurídica que se relacionam na medida em que essencialmente se ocupam dos problemas fundamentais. Não estão, portanto, em uma relação de mais ou menos importância, mas sim em uma relação de alteridade. (KAUFM ANN, 2004, p. 17-28). Nesse sentido, elas coexistem, não sendo substituída uma pela outra, mas sim desempenhando uma função de dialeticidade.

Com relação à Teoria do Direito e a Dogmática Jurídica, muito embora muitos autores se utilizam do termo "Dogmática Jurídica" como sinônimo do termo "Teoria Geral do Direito", outros preferem distinguir os referidos termos, identificando a Teoria Geral do Direito como exame das estruturas formais e dos conceitos jurídicos fundamentais comuns a todas as ordens jurídico-positivas cabendo a Dogmática descrever, interpretar e sistematizar as normas de uma ordem jurídica vigente.

Pontua-se que a Teoria Geral do Direito possui seu ancestral mais próximo na Filosofia. Porém, não se nega que possui grande proximidade com a Dogmática Jurídica, também.

A Teoria Geral do Direito, que em outras épocas já foi prisioneira de dogmas ultrapassados, modernamente apresenta uma proposta de visão global do fenômeno jurídico, reconstruindo conceitos e institutos do direito.

Assim sendo, a moderna Teoria Geral do Direito não deve excluir, por exemplo, a Política, a Sociologia, a Economia, Deontologia e Filosofia, reveladoras da idéia de justiça, devendo ser analisada pelas mais amplas perspectivas de estudo, haja vista que não existe conhecimento isolado, havendo uma interdisciplinaridade do direito e outras ciências.

Em uma análise a priori, pode-se estabelecer que a Filosofia do Direito está mais direcionada para os conteúdos, em vista da Teoria do Direito que direciona-se para as formas. Contudo, sempre levando em consideração que, tendo em vista que não existe matéria sem forma, tampouco forma sem matéria, não se pode assim obter uma delimitação precisa. 
A Teoria do Direito, dessa forma, tem em comum com a Filosofia do Direito o fato de não se limitar ao direito vigente e também não se ocupar dos fatos jurídicos. Porém, ambas se distinguem pelo seu motivo, tendo em vista que a teoria do direito pretende a "emancipação" à Filosofia do Direito.

\section{Aspectos iniciais da Teoria Geral do Direito}

A Teoria Geral do Direito engloba grandes princípios e os aspectos metodológicos do direito, reforçando a tese de que o jurista não deve ser um mero autômato, que aplica servilmente uma regulamentação sem analisar os princípios maiores que o norteiam. A visão do direito tem que ser global, bem como global deve ser a visão quando da elaboração das normas jurídicas. (BERGEL, 2001)

Assim sendo, a Teoria Geral do Direito tem por objetivo destacar os elementos essenciais que dominam a elaboração do direito e exumar os instrumentos e os raciocínios indispensáveis à sua utilização, tudo isso dentro de uma perspectiva metodológica.

Ademais, tem por conteúdo promover a melhora das relações sociais formulando regras justas e aplicando-as de maneira equitativa, sem deixar de lado a criação de regras e suas interpretações, bem como a classificação dos fatos jurídicos, construção de teorias e elaboração de princípios, sempre com o cuidado constante de garantir a segurança jurídica.

Seguindo essa linha, a Teoria Geral deve ser apreendida dentro de uma perspectiva metodológica e tem como objetivo estudar essas grandes questões.

Essa disciplina se faz necessária para a apreensão e aplicação do direito, estudando os princípios, conceitos, instituições, mecanismos que comandam o pensamento jurídico.

No plano prático, para a elaboração e aplicação concreta do direito, os juristas devem recorrer à teoria geral para descobrir, interpretar, executar as soluções possíveis.

Partindo deste prisma, observa-se que cada vez mais o interprete do direito, desde sua formação, até o exercício de sua profissão, deveria focar mais os ensinamentos da Teoria Geral e menos nos meros conhecimentos acumulados. A própria elaboração legislativa deveria ser seguida de método e reflexão jurídica; e os profissionais sairiam ganhando com uma melhor utilização dos instrumentos que a técnica jurídica comporta. Tudo isso alinhado a uma boa compreensão do fenômeno jurídico. 
É inegável que as mudanças sociais, econômicas e políticas refletem sobremaneira nas relações humanas e conseqüentemente na liberdade social e vida social. Nesse contexto, o Direito também sofre suas modificações na medida em que em virtude disso, acentua-se 0 debate sobre si, sua importância, funções e até mesmo sobre o papel da justiça.

Dessa forma, no contexto da sociedade contemporânea, o Direito passa a ser visto sob outro ângulo, na medida em que busca acompanhar as evoluções ocorridas.

Nesse diapasão, observa-se uma "maré legislativa", cujas inúmeras normas editadas a fim de se regular as relações sócias, pelo contrário, passam a causar uma convicção de insuficiência do instrumento legal e certa descrença no direito.

Partindo dessas premissas, destaca-se um fenômeno social que se manifesta, cuja expressão utilizada é o chamado "desencantamento do direito". Esse desencantamento das pessoas tem a ver com o fato de que o direito não só não serve para a justiça, como também é gravemente ineficaz para servir a justiça.

Ainda que os caminhos, métodos e instrumentos para se chegar a uma ordem social mais justa têm sede em outra classe de instrumento e força social que não necessariamente em natureza jurídica, como os movimentos sociais, por exemplo.

Ademais, a ineficácia do direito pode ser devido a um interesse socioeconômico camuflado, que evita a solução dos grandes problemas da justiça por meio do direito, posto que talvez essa solução significaria uma mudança do modelo socioeconômico; ou também pelo fato de uma imensurável dimensão dos grandes problemas de justiça no mundo contemporâneo. Estes seriam argumentos explicativos a essa descrença.

Há que se destacar ainda uma questão extremamente contemporânea, inclusive no Brasil, como forma de ilustrar esse descontentamento com o direito, que é o fato da sobrecarga do poder judiciário (tanto por quantidade, quanto por complexidade).

Cada vez mais diante de casos complexos, as sentenças se propagam no tempo e a justiça de mostra ineficaz ante uma sociedade que sofre conflitos numa rapidez absurda e que demanda soluções rápidas.

Assim, diante de toda essa realidade, está-se diante de uma necessidade de se buscar outras formas de solução de conflitos e de controle social não jurídico.

0 direito está muito atrelado as condições e limitações da liberdade na vida social. Nos tempos atuais, com a ampliação do processo de "juridificação" tanto da vida social 
quanto individual, o direito passa a ser repensado e produz um novo debate agora focado não mais somente para sua restrita interpretação, mas sim com uma exigência maior sobre sua real função e também, sobre o papel da justiça.

Ao mesmo tempo, destaca-se que o direito pode ser pensado como um instrumento para as políticas legislativas e para os juristas na hora de interpretar os casos concretos.

Partindo-se desse novo rumo tomado pelo direito, há que se entrelaçar algumas características sobre o direito e a Teoria do Direito no contexto contemporâneo.

Em principio, como dito acima, esse processo de "juridificação" da vida social permite que 0 direito controle e regule as diversas relações sociais que se direcionadas tendo como base tão somente a pura liberdade das partes, poderiam levar a conseqüências desastrosas. Observa-se aqui a reafirmação do surgimento do direito, que teve início justamente para regular as relações sócias. Surgiu como forma de apaziguar e minimizar os anseios causados pela liberdade de vontades dos indivíduos, como técnica de organização social.

Assim sendo, observa-se uma concepção dominante do direito como técnica de organização social que unida a essa "juridificação" crescente faz com que a Teoria do Direito e conseqüentemente a formação dos juristas se concentrem em um trabalho científico de natureza descritiva e informativa, primando pela boa técnica. Preocupando-se com 0 concreto e com sua melhor solução. Conseqüentemente, há uma recusa a toda possibilidade de politização e edificação do direito na Teoria do Direito.

Os legisladores, os juristas e até mesmo os cidadãos demandam, sobre a Teoria do Direito, propostas concretas para a produção legislativa e para interpretação e aplicação do direito, mas não focam em problemas axiológicos ou políticos sobre o que e a quem serve 0 direito.

Atualmente, as preocupação dos juristas, sejam eles em formação ou já experientes, em sua grande maioria é ser especializarem em determinadas matérias do direito, se tornarem "experts". M as se esquecem de em formar juristas críticos, capazes de resolver problemas concretos, mas sem se desprender dos princípios éticos e políticos, que sirvam de logro a uma sociedade mais igualitária e livre. 
Diante dessa realidade que se instaura, destaca-se a convergência para a necessidade de uma teoria crítica do direito, que surge como contrapartida ao cientificismo positivista, em razão de que a ciência carecia de uma auto-reflexão para conhecer os motivos sociais que a impulsionam.

Assim sendo, essa "nova" Teoria do Direito, impulsionada pela filosofia do direito com vocação critica e utópica se torna um fator decisivo para a formação do futuro jurista. Principalmente, posto que irá abrir novos horizontes e a possibilidade de um uso mais racional das normas jurídicas, por meio do conhecimento crítico, dos efeitos, finalidades e valores em jogo.

O jurista crítico deixará de pensar apenas na técnica procedimental de organização social, mas também nas constatações de que a realidade jurídica não se esgota e nem se pode esgotar em uma simples análise científica das normas jurídica e do ordenamento, mas sim na realidade política, moral, econômica, cultural e histórica.

Assim sendo, a aproximação entre Filosofia e Teoria demonstra que muita das mudanças sócias tem ocorrido diante da importante colaboração de uma filosofia jurídico política.

\section{A nova hermenêutica jurídica face ao modelo de Estado que surge}

O fenômeno jurídico se apresenta como força viva, como um plano da realidade social que é. E partindo deste prisma, e tendo em vista que nas ultimas décadas, sob deliberado enfraquecimento do Estado, vive-se uma certa "crise do Direito", é que se faz necessário abordar a questão referente a "crise da hermenêutica jurídica". (STRECK, 2004)

Em um primeiro momento, partindo-se de uma análise da realidade social vivida, pode-se abarcar que o Direito e a dogmática jurídica não conseguem atender as especificidades das demandas originadas de uma sociedade complexa e conflituosa.

O paradigma liberal-individualista-normativista está esgotado, aliado ao fato do crescimento dos direitos transindividuais e a crescente complexidade social, passa-se a se fazer necessária uma nova postura dos operadores do direito.

Não se pode negar que ainda existe certo abismo entre o Direito e a sociedade, que é instituído e instituinte da crise de paradigma latente. Assim, observa-se retratado certa incapacidade histórica da dogmática jurídica em lidar com a realidade social. 


\section{Implicações filosóficas da Teoria contemporânea do direito: uma análise da aproximação entre teoria e filosofia do direito com vistas à construção do Estado democrático}

Ou seja, cada vez mais, passa a haver uma disparidade entre a compreensão da dogmática jurídica em lidar com os problemas decorrentes de uma sociedade dispare como a nossa.

Destaca-se ainda que no campo jurídico brasileiro, a linguagem tem um caráter secundário, uma terceira coisa que se interpõe entre sujeito e objeto, enfim, uma espécie de instrumento ou veículo condutos das essências dos textos legais. Daí surge a necessidade da elaboração de uma crítica à hermenêutica jurídica tradicional, ainda mais, fortemente assentada no paradigma objetificante da filosofia da consciência. (STRECK, 2004)

No momento em que o mundo é varrido por uma fustigante onda neoliberal, a questão da função do Estado e do Direito passa a ser rediscutida, assim como as condições de possibilidades da realização da democracia e dos direitos fundamentais.

No Brasil, muito embora a modernidade possa ser classificada como tardia e arcaica por diversos pensadores do Direito, o Estado não pode pretender ser fraco, mas cada vez mais forte para garantir os direitos num contexto hostil de globalização neoliberal.

É importante observar ainda que, nesse meio, em nosso país, pode-se dizer ainda em uma crise de legalidade, uma vez que sequer esta é cumprida, bastando para tanto verificar a inefetividade das disposições da Constituição.

Em nosso país, não há duvidas de que, sob a ótica do Estado Democrático de Direito, o Direito deve ser visto como instrumento de transformação social. 0 Direito brasileiro, e a dogmática jurídica, que o instrumentaliza, estão assentados em um paradigma liberal-individualista, que sustenta esta desfuncionalidade, que paradoxalmente vem a ser a própria funcionalidade.

A crise do modo de produção do Direito se instala justamente porque a dogmática jurídica, em plena sociedade transmoderna e repleta de conflitos transindividuais, continua trabalhando com a perspectiva de um Direito cunhado para enfrentar conflitos interindividuais.

Entre os fatores que contribuem para o agravamento dessa problemática estão, 0 excessivo individualismo e o formalismo na visão do mundo.

Estamos assim, diante de um sério problema: de um lado, temos uma sociedade carente de realização de direitos, e de outro, uma Constituição Federal que garante esses 
direitos da forma mais ampla possível. Assim sendo, como pensar o papel do Direito e da Dogmática Jurídica neste contexto?

\section{Estado democrático de direito: uma proposta de efetivação dos direitos fundamentais}

A noção de Estado Democrático de Direito está indissociável da realização dos direitos fundamentais. Cabe, pois, agora, buscar mecanismos de efetivação e concretização destes.

Neste contexto, as propostas do Estado, principalmente do chamado Estado Providência ou Estado Social, não são cumpridas, criando-se um choque entre a realidade e o Estado de Direito. O Direito deve ser visto como instrumento de transformação social, de construção de um Estado Democrático de Direito.

Todavia, as crises são possibilidades de superação, tornando-se necessário recuperar as possibilidades do Direito como elemento de transformação emancipatória.

Assim sendo, o Poder Judiciário deve assumir uma postura intervencionista, através do controle de constitucionalidade das leis, por exemplo, podendo servir como via de resistência às atividades dos Poderes Executivo e Legislativo. Ademais, o Judiciário deve ser instrumento para o desenvolvimento de políticas públicas também, ou seja, por meio dele é possível exigir das autoridades que cumpram seus deveres.

Não se pode deixar de apontar ainda a superação do paradigma normativista, próprio de um modelo de Direito liberal-individual.

Apesar de tudo isso, o Direito, instrumentalizado pelo discurso dogmático, consegue aparecer aos olhos do operador do Direito como, ao mesmo tempo, seguro, justo, abrangente, técnico e funcional.

E diante de tudo isso, precisa-se repensar a dogmática jurídica, com efeito, inserida em uma forte crise de paradigmas, que sustenta a (dês) funcionalidade do Direito.

E é nesse sentido que se faz necessário repensar o Direito, com vistas à construção de um novo Estado Democrático de Direito, pautando-se em valores como dignidade, solidariedade e na busca pelo reconhecimento dos direitos fundamentais dos cidadãos. 
Implicações filosóficas da Teoria contemporânea do direito: uma análise da aproximação entre teoria e filosofia do direito com vistas à construção do Estado democrático

\section{Constitucionalização do direito e Estado democrático}

A constitucionalização do Direito é o processo e o resultado da transformação do Direito causado pela Constituição.

Existem certos requisitos caracterizadores do constitucionalismo do Direito, dentre tantos, a influência da Constituição nas relações políticas, em que os princípios constitucionais, de forte carga moral e valorativa, intervêm na argumentação política, reforçando a idéia de unidade o ordenamento, hipótese em que também haverá a aplicação e interpretação das leis conforme a Constituição. (BONAVIDES, 2001)

Necessário relatar que a constitucionalização do ordenamento jurídico não se limitou a transformar apenas o Direito, mas também o estilo de pensamento de juristas e teóricos.

Assim sendo, esta constitucionalização têm dado lugar ao neoconstitucionalismo em que é o conjunto de teorias que têm proporcionado uma cobertura jus teórica conceitual e normativa à constitucionalização do Direito em termos geralmente não positivistas.

Esse neoconstitucionalismo tem influenciado fortemente certos aspectos implícitos na constitucionalização principalmente os aspectos materiais (sistema jurídico ligado conceitualmente à moral) e estruturais (ampliação do âmbito da influência da constitucionalização através dos princípios constitucionais, com base na argumentação prática) e políticos (acentuação do Poder Judiciário perante o Legislativo).

Assim sendo, faz-se mister apresentar alguns exemplos de constitucionalismo: Constitucionalismo teórico - apresenta caráter descritivo, sendo uma vertente mais eficaz do constitucionalismo, em que a constitucionalização dos sistemas jurídicos torna inviável o positivismo teórico; Constitucionalismo ideológico - apresenta caráter normativo, em que a constitucionalização dos sistemas jurídicos exclui a existência de um dever de obediência ao Direito; Constitucionalismo metodológico: é a concepção mais importante para uma relação conceitual entre Direito e Moral.

A constitucionalização do ponto de vista jurídico oferece uma estrutura mais ampliada do que o próprio sistema jurídico; do ponto de vista histórico, os princípios juntamente com o constitucionalismo é superior ao argumento da justiça; do ponto de vista sócio-político, o constitucionalismo responde melhor as necessidades da sociedade política e as culturas plúrimas. 
A constitucionalização dos sistemas jurídicos tem contribuído para a criação deste vínculo, através do discurso filosófico-jurídico, a ponto de criar uma nova Teoria do Direito, ainda em construção, que tem como pressuposto o paradigma do Estado Constitucional de Direito. Assim sendo, cumpre agora estabelecer o ponto entre este processo de constitucionalização do Direito e a formação do Estado Democrático. (COELHO, 2007)

O Estado Democrático de Direito se diferencia dos modelos anteriores - Estado Liberal e Estado Social, sem mencionar ainda o Estado Absolutista, anterior a estes - por superá-los política, econômica, social e ideologicamente, congregando dois princípios de longa trajetória histórica: o Princípio democrático e o do Estado de Direito (GOM ES, 2001). Todavia, a democracia e os direitos fundamentais passam a ser os dois sustentáculos desse novo modelo, donde não pode haver retrocesso (STRECK, 2004).

No Estado de Direito Democrático, a Constituição vincula todos os poderes a suas normas. Nesse contexto, legislar, administrar e julgar são funções a serem exercidas dentro dos limites constitucionais.

Toda norma jurídica, para ser aplicada a situações concretas, precisa ser interpretada, isto é, entendida em seu significado, cabendo a hermenêutica jurídica propiciar instrumentos adequados à interpretação do Direito.

É necessário ressaltar algumas características básicas e essenciais dos modelos liberal e social. 0 primeiro proclamava pela igualdade de todos perante a lei, a qual buscava proteger a esfera individual de qualquer interferência arbitrária do Estado, que se transformou em um Estado mínimo. Os direitos fundamentais reconhecidos eram os individuais.

Porém, o abuso da liberdade exercida sem limites gerou uma enorme disparidade econômica, com uma enorme massa de miseráveis, o que propiciou a ascensão do Estado Social, de caráter intervencionista, provedor do bem estar social. Tal modelo tendia ao socialismo, autoritarismo e ao totalitarismo. Predominava 0 interesse em atender os interesses grupais, da classe trabalhadora, fonte de toda a produção, mas não os interesses individuais, de cada pessoa humana. Os direitos fundamentais eram somente os sociais.

0 professor Guerra Filho lembra que a fórmula do Estado Democrático se firma a partir de uma revalorização dos clássicos direitos individuais de liberdade, que se entende não poderem jamais ser demasiadamente sacrificados, em nome da realização de direitos 
sociais. Representando, então, uma forma de superação dialética da antítese entre os modelos liberal e social ou socialista de Estado. Em sendo assim, tem-se o compromisso básico do Estado Democrático de Direito na harmonização de interesses que se situam em três esferas fundamentais: a esfera pública, ocupada pelo Estado, e a esfera privada, em que se situa o indivíduo, e um segmento intermediário, a esfera coletiva, em que se tem os interesses de indivíduos enquanto membros de determinados grupos, formados para a consecução de objetivos econômicos, políticos, culturais ou outros (GUERRA FILHO, 2005, p. 24).

Contudo, não se pode negar ainda a presença de um papel transformador do Estado Democrático de Direito, apontando os seus seguintes princípios: por primeiro, a Constitucionalide - vinculação do Estado Democrático de Direito a uma Constituição como instrumento básico de garantia jurídica; Também, a Organização Democrática da Sociedade; e o Sistema de direitos fundamentais individuais e coletivos, seja como Estado de distância, porque os direitos fundamentais asseguram ao homem uma autonomia perante os poderes públicos, seja como um Estado antropologicamente amigo, pois respeita a dignidade da pessoa humana e empenha-se na defesa e garantia da liberdade, da justiça e da solidariedade;

Não se pode deixar de abordar a Justiça Social como mecanismos corretivos das desigualdades; juntamente com a Igualmente não apenas como uma possibilidade formal, mas, também, como articulação de uma sociedade justa;

Por fim, destacam-se a Divisão de Poderes ou de Funções; Legalidade que aparece como medida de direito, isto é, através de um meio de ordenação racional, vinculativamente prescritivo, de regras, formas e procedimentos que excluem o arbítrio e a prepotência; e Seguranças e Certezas Jurídicas.

\section{Hermenêutica jurídica e a concretização do Estado democrático de direito}

A hermenêutica é o estudo do compreender, é sempre uma compreensão de sentido: buscar o ser que me fala e o mundo a partir do qual ele me fala; descobrir atrás da linguagem o sentido radical, ou seja, o discurso.

Nessa seara, deve-se ter em mente que não faz sentido falar em hermenêutica jurídica desvinculada da interpretação. A primeira fornece os meios adequados à boa 
realização da segunda, a qual também não se exaure em si mesma, pois ganha razão de ser quando encontra espaço para a efetiva aplicação das normas jurídicas em situações concretas das relações intersubjetivas, tendo-se em conta a dimensão prática do direito.

A finalidade precípua da hermenêutica jurídica consiste em fornecer os meios adequados à interpretação - busca de sentido - e integração - preenchimento de lacunas das leis e do direito. Diante disso, conseqüentemente, a hermenêutica jurídica não se confunde com a interpretação.

A "Nova Hermenêutica Jurídica" deve corroborar para a concretização do Estado Democrático de Direito se assumir um papel/função constitucional capaz de efetivar tanto os direitos fundamentais como o princípio democrático.

Deve haver uma consciência plena do hermeneuta neste sentido, aplicando os valores inerentes ao ideal constitucional no caso concreto e nas relações sociais de uma sociedade que anseia por um tratamento digno e carente de desenvolvimento completo em sua essência, enquanto seres individuais e em comunhão de vida com outros semelhantes, para a satisfação de suas "necessidades básicas". É através da hermenêutica constitucional que se busca a melhor interpretação e concretização do ordenamento jurídico vigente, que foi positivado mediante a adoção de princípios, valores e objetivos que norteiam o Estado de Direito Democrático. A consciência desta nova hermenêutica deve estar aguçada no intelecto do intérprete jurídico para a plena satisfação e concretização do Estado Democrático de Direito.

Com relação ao tema, destaca-se o pensamento de Sérgio Alves Gomes, em seu livro Hermenêutica Constitucional, demonstrando uma sensibilidade social ao fundamentar, nos seguintes dizeres:

[...] para 'dar vida à Constituição' do Estado Democrático de Direito exige-se uma hermenêutica que combata a morte do ideário democrático. Por isso, urge se pense em uma hermenêutica capaz de desenvolver em todos os intérpretes - e na democracia todos têm o direito e o dever de interpretar a Constituição, visando a sua compreensão - a consciência de que a Constituição deve ser entendida como algo muito superior a uma simples 'folha de papel' (lembrando a expressão de LASSALLE). Tal compreensão há de estar presente na consciência de todos e deve ser exteriorizada de modo exemplar pelo comportamento de quem exerce o poder público e, sobretudo, daqueles a quem compete, institucionalmente, a defesa substancial e processual da Constituição, como é o caso dos que exercem a Advocacia, integram o Ministério Público ou são órgãos do Poder Judiciário. (GOMES, 2006, p. 343) 


\section{Implicações filosóficas da Teoria contemporânea do direito: uma análise da aproximação entre teoria e filosofia do direito com vistas à construção do Estado democrático}

No primeiro artigo da Carta Magna verifica-se que do princípio do Estado Democrático, se extraem outros denominados de "Princípios Fundamentais"; dentre estes, distingue-se os "princípios fundamentais estruturantes" dos "princípios fundamentais gerais" e, ainda, abaixo deles, os "princípios constitucionais especiais", seguidos das normas constitucionais que não são princípios, mas regras.

Sendo os direitos fundamentais, juntamente com a democracia, são, nas palavras de Streck, o sustentáculo do Estado Democrático de Direito e cabe a este promover a efetividade daqueles - dos direitos fundamentais - em todas as modalidades que se apresentam, eis que foi o reconhecimento do princípio da dignidade humana, em forma de princípio fundamental do Direito Constitucional e do Direito Internacional dos Direitos Humanos, que levou à instituição do Estado Democrático de Direito, de maneira a assentarse sob as bases daquele princípio, juntamente com o princípio democrático. (STRECK)

A "aplicação" do Direito pressupõe antes de tudo interpretar (e aplicar) o ordenamento jurídico à luz dos ideais da Constituição (interpretação constitucional), o que se possibilita a efetividade da concretização dos direitos fundamentais e do princípio democrático, sustentáculos do Estado Democrático de Direito.

Porém, muitos são os obstáculos enfrentados para a concretização dos direitos fundamentais, principalmente em países emergentes, como o caso do Brasil.

Dentre estes obstáculos destaca-se a ausência de vontade de se transformar a realidade por meio da ação humana, seja por parte de governantes, ou até mesmo da população em si; falta de solidariedade entre as pessoas e as nações; o regime em que se tolhe a liberdade individual ao ponto de se colocar o Estado, como fim, e o homem, na qualidade de instrumento deste; uma ausência de limites à liberdade econômica que gera a miséria de milhões de pessoas, como a adoção de um regime liberal-indvidualistanormativo, etc.

Neste sentido, pode-se afirmar que se opõem à concepção democrática, ora em apreço, todos os atos, oriundos de indivíduos, grupos, Estados soberanos ou quaisquer organismos, que contribuam de alguma forma para a redução da pessoa humana a um objeto, a um meio que possa ser utilizado como mero instrumento para seu "usuário" atingir objetivos egoísticos, descompromissados com qualquer preocupação alusiva ao crescimento do semelhante (GOM ES, 2008). 
Contudo, mesmo com esses inúmeros obstáculos, o foco de atenção deve estar voltado para a superação dos mesmos, embora a identificação deles não deva ser mencionada como sem importância. Mas ainda mais importantes são as possibilidades de superação dos mesmos.

O jusfilósofo Sérgio Alves Gomes apresenta a solução tão esperada e tão propagada há tempos, mas nunca levada a sério e sempre negligenciada por governos/governantes interessados na manutenção do (infeliz) status quo:

\begin{abstract}
Todavia, sejam quais forem os obstáculos e a natureza destes só poderão ser superados com a união de esforços de toda a sociedade organizada, de suas instituições e das pessoas que exercem o poder e a influência no âmbito destas. 0 processo da democracia é também - tal como o ser humano - complexo e multidimensional. Não se deve jamais dele abdicar e nem esperar que um governo o realize sozinho. Vai ganhando concretização histórica à medida que os diversos quadrantes da sociedade se sentirem tocados, sensibilizados, pela chama dos valores democráticos. No entanto, as fagulhas destes valores - qual fogo reanimador dos mortais, nas mãos de Prometeu - somente se espalharão por meio da educação. Só ela é capaz de resgatar dos guetos da ignorância e da miséria aqueles que estão privados das luzes do conhecimento. Em síntese, cabe à educação produzir lentes que auxiliem na percepção e respeito do valor da dignidade presente em todo e qualquer ser humano. Sem ela, (educação) o Direito e suas leis passam a ser utilizados abusivamente como meros instrumentos de dominação, o que leva a frustração dos que almejam uma sociedade menos injusta e mais solidária do que a existente, ou seja, uma sociedade genuinamente democrática. (GOMES, 2001)
\end{abstract}

Para que este ideal - a educação como instrumento de afirmação da dignidade da pessoa humana, implicando na evolução e transformação da própria pessoa - realmente se efetive é necessário um maciço investimento de recursos públicos alocados a este setor e uma extrema e irrestrita vontade de fazer por parte dos dirigentes governamentais, com vistas ao cidadão numa relação sujeito-sujeito e não sujeito-objeto, onde ele é visto como instrumento e não como fim pelo Estado.

A preocupação com os direitos fundamentais e a democracia engendra textos constitucionais que avançam nitidamente em relação aos fundamentos do velho liberalismo e à noção puramente intervencionista do Estado Social. A democracia e os direitos fundamentais passam a ser os dois sustentáculos desse novo modelo, donde não pode haver retrocesso. Assim sendo, é possível dizer que o agir jurídico-político dos atores sociais encarregados institucionalmente de efetivar políticas públicas acontece nessa manifestação prévia, onde já existe um processo de compreensão. 


\section{Implicações filosóficas da Teoria contemporânea do direito: uma análise da aproximação entre teoria e filosofia do direito com vistas à construção do Estado democrático}

Os valores entendidos como fundamentais pelos seres humanos são derivados de uma evolução lenta da humanidade, e de uma atitude voluntária e coletiva da sociedade em busca de uma melhor convivência humana.

Com o passar dos anos, os direitos humanos e fundamentais, principalmente 0 respeito à dignidade da pessoa humana, se tornaram componentes nucleares da idéia de democracia e, conseqüentemente, componentes nucleares da idéia de Estado Democrático de Direito.

Com efeito, o Estado Democrático de Direito reflete uma sociedade comprometida com os ideais democráticos, ou seja, reflete uma sociedade que faz esforços para concretizar esses valores fundamentais, que somente se tornam possíveis pela aprovação democrática de uma Constituição.

Ora o Estado Democrático de Direito assenta-se em dois pilares: a democracia e os direitos fundamentais. Não há democracia sem o respeito e a realização dos direitos fundamentais - sociais, e não há direitos fundamentais - sociais sem democracia.

Destarte o paradigma do Estado Democrático de Direito se liga, inexoravelmente, à função transformadora que o Direito assume. Da idéia de Direito como ordenação e até mesmo de promoção, exsurge um papel para o Direito que vai muito além da Constituição enquanto mero instrumento para a aferição da parametricidade formal. Isto, a toda evidência, demandou um novo tipo de concepção acerca da jurisdição constitucional, representada pela instituição de tribunais constitucionais, também conhecidos como tribunais ad hoc, aptos a "instrumentalizar" e dar guarida à materialidade dos textos constitucionais.

Partindo deste raciocínio, ao se desenvolver uma reflexão filosófico-jurídica envolvendo hermenêutica, seja ela constitucional, filosófica, ou até mesmo jurídica, refletindo nas possibilidades de se atingir um Estado Democrático de Direito, deve-se analisar que este paradigma estatal passa a ser visto como não somente como uma instituição social, mas também como uma constituída pela sociedade para ordená-la por meio de princípios fundamentais à convivência humana.

Portanto, o diálogo entre Filosofia do Direito e Hermenêutica Constitucional funciona como um contrapeso que traz muitas possibilidades de questionamento e de 
horizontes à compreensão do que se espera do Direito, do Estado Democrático de Direito e da Hermenêutica Constitucional.

\section{Conclusão}

Assim sendo, notório destacar que o Estado Democrático de Direito reflete uma sociedade comprometida com os ideais democráticos, ou seja, reflete uma sociedade que faz esforços para concretizar valores fundamentais, que somente se tornaram possíveis pela aprovação democrática de uma Constituição.

Observou-se que o Estado Democrático de Direito assenta-se em dois pilares, quais sejam, a democracia e os direitos fundamentais, não havendo democracia sem o respeito e a realização dos direitos fundamentais - sociais, e não há direitos fundamentais - sociais sem democracia.

Destarte o paradigma do Estado Democrático de Direito se interliga à função transformadora que o Direito assume. Ou seja, o Direito como ordenação e até mesmo de promoção, que vai muito além da Constituição enquanto mero instrumento, mas sim uma nova concepção acerca da jurisdição constitucional, representada pela instituição de tribunais constitucionais, aptos a "instrumentalizar" e dar maior efetividade à materialidade dos textos constitucionais.

\section{Referências}

BARROSO, Luís Roberto; BARCELLOS, Ana Paula. O Começo da História. A Nova Interpretação Constitucional e o Papel dos Princípios no Direito Brasileiro. In: BARROSO, Luís Roberto. A Nova Interpretação Constitucional: ponderação, direitos fundamentais e relações privadas. Rio de Janeiro: Renovar, 2003.

BERGEL, Jean-Louis. Teoria Geral do Direito. Tradução de Maria Ermantina Galvão. São Paulo: Martins Fontes, 2001. p.xv-xxx.

BONAVIDES. Paulo. Teoria Constitucional da Democracia Participativa. São Paulo: Malheiros, 2001.

CALERA, Nicolas M . López. Derecho y teoría del Derecho em el contexto de la sociedade contemporánea. In:OLIVEIRA JUNIOR, José Alcebíades de. 0 novo em Direito e Política. Porto Alegre: Livraria do Advogado, 1997. 
COELHO, Luiz Fernando. Direito Constitucional e Filosofia da Constituição. Curitiba: Juruá: 2007.

FIGUEROA, Alfonso García. La Teoria del Derecho em Tiempos de Constitucionalismo. In: CARBONEL, Miguel (Org.). Neoconstitucionalismo(s). Madrid: Trotta, 2003.

GOM ES, Sergio Alves. Hermenêutica Constitucional: um Contributo à Construção do Estado Democrático de Direito. Curitiba: Juruá, 2008. Janeiro, 2001.

. Hermenêutica e Constituição no Estado de Direito Democrático. 2. ed. Rio de . 0 princípio Constitucional da Dignidade da Pessoa Humana e o Direito Fundamental à Educação. Revista de Direito Constitucional e Internacional, São Paulo, n. 51, abr./jun. 2005.

. Possibilidades da hermenêutica constitucional na construção do Estado Democrático de Direito. 2006. 343 p. Tese (Doutorado) - Pontifícia Universidade Católica, São Paulo, 2006.

GUERRA FILHO, Willis Santiago. Processo Constitucional e Direitos Fundamentais. 4. ed. São Paulo: RCS, 2005.

GUERRA FILHO, Willis Santiago. Teoria da Ciência Jurídica. São Paulo: Saraiva, 2001.

KAUFM ANN, Arthur. Filosofia do Direito. Tradução de António Ulisses Cortês. Lisboa: Fundação Calouste Gulbenkian, 2004.

M ACHADO NETO, Antônio Luís. Teoria da Ciência Jurídica. São Paulo: Saraiva: 1975.

STRECK, Lenio Luiz. Jurisdição Constitucional e Hermenêutica: uma Nova Crítica do Direito, 2. ed. Rio de Janeiro: Forense, 2004

ZACCARIA, Giuseppe. Implicações Filosóficas de la Teoria Contemporânea del Derecho. In: . Razón Jurídica e Interpretación. Madrid: Civitas, 2004. p. 17-32. 